
\title{
25 Research Square \\ Effect of family member's counseling on postnatal perceived stress in Iranian women: a Randomized Controlled Trial
}

fatemeh moghaddam-tabrizi ( $\sim$ fmtabrizi@gmail.com )

Urmia University of Medical Sciences

Parivash Noorkhah

Urmia University of Medical Sciences

Research article

Keywords: Family Involvement, Postnatal Perceives Stress, Pregnancy

Posted Date: December 1st, 2019

DOI: https://doi.org/10.21203/rs.2.17778/v1

License: (c) (1) This work is licensed under a Creative Commons Attribution 4.0 International License.

Read Full License 


\section{Abstract}

Background \&Aims: Family members' support during postnatal period is so important for women and neonates health. The purpose of the present study was to determine the effect of counseling with family member's on postnatal perceived stress in Iranian women.

Methods: In this randomized clinical trial a group of 294 women and their husbands and family members randomly allocated into two intervention (149) and control (145) groups. Women in intervention group received involvement program. Both groups completed the Postnatal Perceived Stress Inventory, and a demographic questionnaire. Data were analyzed using Mann-Whitney $\mathrm{U}$, Wilcoxon tests and independent t-test. $P$ value less than 0.05 was considered significant.

Results: Findings revealed a significant reduction in total postnatal perceived stress $(t=8.93, p<0.001)$ and in it's all subscales including fatigue $(t=6.55, p<0.001)$, relationship with baby $(t=2.63, p<0.001)$, relationship with body $(t=6.43, p<0.001)$, feeding the baby $(t=2.16, p<0.001)$, future plan $(t=10.29$, $p<0.001)$ and in relationship with partner $(t=10.83, p<0.001)$.

Conclusion: Involvement husband and family members could empower women to overcome stressors and reduce postnatal perceived stress.Keywords: Family Involvement, Postnatal Perceives Stress, Pregnancy

\section{Background}

The postpartum period or puerperium is a transitional time and is a potentially stressful period because a woman needs to face both the new tasks of her maternal role and changes in her body [1]. The puerperium is a crucial time of transition in the lives of new mothers, coincidences by several physiological, emotional and psychosocial changes that begin soon after birth and can continue till the end of the first year of life of the child [2].

Postpartum anxiety and stress is widespread, with prevalence ranging from $2 \%$ to $45 \%$ in the first year postpartum $[3,4]$. Along with postpartum stressors such as sleep deprivation, hormonal diversity, and the requirement of caring of a neonate, first-time mothers have to adjust to their new parenting role $[5,6]$. First-time mothers may feel uncertain about their capabilities to care of newborn [7]. They often feel devastated, extremely tired, and abandoned in their new roles [8,9]. Studies have indicated that first-time mothers are at a higher risk of postpartum mental disorders in compare to multiparous women [10-12].

Postnatal responsibilities also can cause anxiety and stress, which can be associated with difficulties in adapting of maternal role with prevalence between 33\% and 59\%[13]. Furthermore, it can disturb the development of the mother/infant relationship [14]. Studies demonstrated that concerns about negative body changes, maternal role and lack of social support are three causes of postpartum stress $[15,16]$. Social support has been shown to be effective in helping women to cope with these stressors[17]. Low levels or inconsistent social support is a strong predictor of postpartum depression[18]. Husbands and 
family members support has been found to be important to women's postpartum health and lack of sufficient support is inversely related to the risk for postpartum depression [19]. Even though postpartum stress has been recognized to specifically associate with minor postpartum psychiatric disorders[20, 21] such as postpartum depression[22, 23] [22, 23] and anxiety [24], very few researches have elucidated interventions with emphasizing to family members role, designing to decrease postpartum stress.

There is limited information regarding the effective role of the husbands and family members involvement during postpartum and childbirth in Iran. So this study conducted to assess the effect of counseling with family member's on postpartum perceived stress in nulliparous Iranian women.

\section{Materials And Methods}

This double-blind randomized controlled trial (Registration ID in IRCT: IRCT2017031720778N18) was conducted in Urmia, in North West of Iran. Women with following criteria were recruited in this study: primiparous women in postpartum period, aged 20 to 35, and understanding the Persian language. Women with following criteria were excluded from the study; having systemic diseases such as diabetes, hypertension, cardiac diseases, stressors events in the past 6 months, using psychotropic drugs and alcohol, women with general health disorders (screened by General Health Questionnaire). Women who consented to participate were randomly assigned to the intervention and control groups, based on the cards A (control group) and B (intervention group).

Sample size was calculated based on the results of a study conducted by Osman et al. with a confidence level of $95 \%$ and a power of $80 \%, 132$ women with adding $20 \%$ as attrition in sample, 165 were identified in each group.

\section{Sampling and research procedure}

A multistage cluster sampling applied. First, Urmia (located in North West of Iran), divided into five areas: center, north, south, west, and east. In each of these areas, all public health centers were known. Four public health centers in each area were randomly chosen. From the determined centers, the number of samples (165) were selected in the form of relative proportions. Women were invited to participate the study by midwife in the health centers and provided an informed consent and randomly assigned into two groups. Then they asked to complete the general health questionnaire, and the Multidimensional Scale of Perceived Social Support (MSPSS).

\section{Measures}

\section{Demographic characteristic}

A questionnaire was used to obtain information such as age, type of delivery, education level, economic status and family members. 


\section{General Health Questionnaire $\left(G H Q_{28}\right)$}

General Health Questionnaire $\left(\mathrm{GHQ}_{28}\right)$ was used to screen the subjects' mental health. The $\mathrm{GHQ}_{28}$ consists of four subscales including somatic symptoms (items 1-7), anxiety/insomnia (items 8-14), social dysfunction (items 15-21) and severe depression (items 22-28). All items are responded on a 4point Likert scale of none, mild, moderate, and severe which were scored from zero to three. The score 23 or above was the cut-off point for probability of having a mental disorder[25]. Accordingly, women who obtained scores $>23$ were excluded from the study. The Persian version of $\mathrm{GHQ}_{28}$ questionnaire was validated by Yaghoubi, et al [26].

\section{Multidimensional scale of perceived social support (MSPSS)}

The MSPSS is a tool to measure the perceived social support (emotional, instrumental, informational, and appraisal) from three sources of individuals' social lives: family, friends, and significant others. This scale developed by Zimet et al. in 1988, contains 12 items[27]. The 7-point Likert-type scale was used for measurements, with ratings from " 1 = strongly disagree" to " 7 = strongly agree." The range of possible scores is $12-84$, with higher scores representing higher levels of perceived social support. The validity and reliability of MSPSS was approved by Zimet et a $[27,28]$. The Persian version of MSPSS was validated in Iran by Salimi et al [29].

\section{The Postnatal Perceived Stress Inventory}

The Postnatal Perceived Stress Inventory developed by Razurel et al. [30] was used to measure postnatal perceived stress. It is an instrument with a 27-item rated on a four-point response format with $1=$ not at all; 2 = a little; 3 = moderately; 4 = very; and 5 = extremely. It consists of domains of fatigue and organization at home (5 items); relationship with baby ( 6 items); relationship with body ( 5 items); feeding the baby (4 items); future plans ( 3 items); and relationship with partner (4 items). The total scores of the scale ranges from 27 to 135 with a higher score indicating a more perceived stress. For this study, the Postnatal Perceived Stress Inventory was translated into Persian using the following steps: (i) the original English instrument was translated into Persian by one of the researcher

$\mathrm{s}$, (ii) the Iranian version was translated back into English by a bilingual professional person who has not seen the original English version and (iii) the three versions were then compared. Unclear or incorrect translations were discussed between the researcher and the professional translator until agreement was obtained. Thus, the translation process followed the recommendations provided by the California Academic Press [31]. For present study the Cronbach's alpha for the total scale was measured to be 0.89 . The alpha coefficients for the subscales ranged from 0.699 to 0.898 . The content validity ratio (CVR) was $76.77 \%$ and content validity index $(\mathrm{CVI})$ was $82.33 \%$ which are acceptable.

\section{Ethical Considerations}


The research protocol was approved by the institutional review board and the Ethics Committee of the Urmia University of Medical Sciences (Ref No: Ir.umsu.rec.1395.109). Participants were provided with detailed information about the study and were assured that confidentiality would be maintained at all times. Written consent was obtained prior to data collection.

\section{Intervention}

The intervention included individual and group consultation for family, in six sessions with 5-6 participants and one active family member. Every session lasted 1.5-2 hours in each week. Through the sessions, the researcher discussed every simple item in postpartum challenges which may produce stress. Women received a notebook to record their thoughts, feelings and all experiences toward the issues that make them feel stress, anxiety and worries. During the sessions, researcher as a facilitator encouraged them to discuss about their negative and positive experiences. For homework, participants monitored and recorded their fatigue, sleep, rest, activity, breast feeding patterns, relationships and other items. Women in the control group did not receive any intervention and they participated in the program after the completion of intervention. The sessions' content are shown in table 1.

\section{Statistical analysis}

Data were analyzed using SPSS software (version 20). Non-parametric Mann-Whitney U test, Wilcoxon test and independent t-test were used for statistical analyses. The normal distribution of data was assessed using the Shapiro-Wilk test. The significance level was set $<0.05$.

\section{Results}

The findings indicated that demographic, clinical characteristics and the mean of family support were homogeneous in the two groups ( $p>0.05)$. (Table 2).

Regarding the effects of intervention our findings revealed a significant reduction in total postpartum perceived stress in the intervention group compared to the control group $(t=8.93, p<0.001)$. Also the subscales of perceived stress including fatigue $(t=6.55, p<0.001)$, relationship with baby $(t=2.63$, $p<0.001)$, relationship with body $(t=6.43, p<0.001)$, feeding the baby $(t=2.16, p<0.001)$, future plan $(t=-$ $10.29, p<0.001)$ and in relationship with partner $(t=-10.83, p<0.001)$ improved in the intervention group compared to the control group. (Table 3 ).

\section{Discussion}

The current resaerch was designed to assess the effect of counseling with family members to reduce the postpartum percieved stress. 
The findings reaveled significant decrease in perciveded stress in intervention group compared to the control group. In the other word the present study highlited the crucial role of family members to help new mothers to cope with postpartum period stress. Regarding percived stress subscales, the result of our study showed that effecive involvement of family members to support of the mothers is also essential to reduce the post partum stress in all dimentions. Other studies confirm the results of the present study about the crucial role of family members as an influential factor to deal with stress of new mothers [19, 32]. In this line the results of a study conducted by Billings et al. showed a significant relation between lack of husband's support and high degree of perceived stress [33]. Other studies pointed out that with higher family support, the level of stress will decrease in pregnancy and postpartum period [34, 35]. Also Kehoe et al. in their study revealed that, mothers of newly born twins require family support to cope with stress [36]. Further, Eddins et al, and Colut et al. found that in newly mothers and in attachment period especially at the earliest moments of newborn's life there is a significant association among depression level, domestic violence, drug use/abuse disappointment, anxiety and more stress[37].

One of the aspects of the MSPSS questionnaire is "fatigue and organization at home". Our intervention could significantly reduce fatigue in mothers compared to the control group. In agreement with the present study Gialloet al. demonstrated that the parents described unrelenting physical and cognitive symptoms of fatigue, and its impact on daily functioning, well-being, and parenting. Sleep deprivation was seen to contribute to fatigue for both mothers and fathers, however, mothers also emphasized that daily demands and limited opportunities for a rest are contributed to their fatigue. Parents need taking time out for, exercise and social support especially family support as a way of managing fatigue[38].

The impression of not being able to look after my baby, baby's health, the risk of stillbirth, caring for the baby are mentioned in relationship with baby subscale and the current study illustrated that involving new fathers and other family members created an appreciative support to diminish perceived stress in this threatening and stressful situation. Concurrent with our results, other studies indicated that mothers with higher scores on the preoccupied and fearful attachment scales had more severe postpartum anxiety and depression symptoms [39]. And also mothers reported moderate to low stress, with parental role alteration in NICU-related stress [40].

Regarding feeding the baby, pain during breastfeeding, uncertainty about baby's sufficient eating, difference between expected and actual experience of breast feeding were mentioned by mothers. In agreement with our study other investigates expressed the family supporting role as a modifier for the major concern regarding breast feeding in newly mothers [41-44].

In regard to relationship with body as another subscale of perceived stress scale, episiotomy scars and perineal tears, recovering sexual intimacy, and painful scar were mentioned. The findings of the present research elucidated that family members had admirable effect to relief the post-partum perceived stress. In Iranian culture grandmother and other close family usually company the women in post-partum period so this issue provide an opportunity for the new mother to take more rest. In agreement with our study, 
other studies indicated that mothers expressed the need to be accompanied and counseled when problems arose and regretted the lack of long-term postpartum support $[45,46]$.

In relationship with partner as the other subscale of the post-partum perceived stress two items; relationship with partner and father's role with the baby were mentioned. A study conducted in Canada depicted that women with depressive symptoms at 8-weeks postpartum had significantly lower perceptions of relationship-specific and postpartum-specific partner support and significantly higher levels of relationship conflict than women with no depressive symptoms[47]. In this line Schlagintweit et al. in their study revealed that a wide range of postpartum sexuality concerns was highly prevalent and moderately distressing for new mothers and fathers. New fathers had a more serious concern about postpartum sexual relationship and also their satisfaction with sexual relationship was decreased. Whereas new mothers' greater severity of postpartum sexual concerns was associated only with lower relationship satisfaction in new fathers. In addition, new mothers' greater frequency of postpartum sexual concerns was associated with their own and new fathers' lower relationship satisfaction[48]. These studies confirm the results of the present study regarding husband's praiseworthy role to manage perceived stress in postpartum of their wives.

\section{Limitation}

The limitations of this study is that some family members did not attend counseling sessions at the beginning of the study. The researcher tried to provide a privet situation during the counseling sessions, to maximize collaboration and coordination with the families and to remind them by phone prior to the sessions.

\section{Conclusion}

The results of our study illuminated that family member's involvement created appreciative opportunity for women during post-partum period and played an instructive role for empowering women for managing the stressors to reduce post-partum perceived stress. The results showed that these kinds of abilities to overcome to the stressful situation can be motivated by family member's encouragements and their admired support.

\section{Declarations}

\section{Acknowledgements}

This research is a midwifery Master's degree thesis with Ethic code of IR.umsu.rec.1395.283 in Uremia University of Medical Sciences. Special thanks to research principal of the University and all women during post-partum and their families who took part in this research.

\section{Funding}


This research was supported by the Uremia University of Medical Sciences. The funding source was not involved in the design, collection, analysis and interpretation of data, in the writing of the report, or in the decision to submit the manuscript for publication.

\section{Availability of data and materials}

The data set is available from the corresponding author on reasonable request.

\section{Authors' contributions}

FMT in the position of the supervisor contributed to the study design, the accuracy of the data analysis, writing the manuscript, and is the guarantor of this work. $\mathrm{HN}$ as the master's student participated as investigators and collecting the data. Both authors read and approved the content of the manuscript.

\section{Author's information}

FMT is a PhD, associate professor in Midwifery Department. HM was a master's student in midwifery consultation in Urmia university medical sciences.

\section{Ethics approval and consent to participate}

The research protocol was approved by the institutional review board and the Ethics Committee of the Uremia University of Medical Sciences (Ir.umsu.rec.1395.109). Participants were provided with detailed information about the study and were assured that confidentiality would be maintained at all times. Written consent was obtained prior to data collection.

\section{Consent for publication}

Not applicable.

\section{Competing interests}

The authors declare that they have no competing interests

\section{References}

1. Henriques, C.M.G., M.A.R. Botelho, and H.d.C.B.P. Catarino, Transition to the Maternal Role in Women with Addiction Problems to Psychoactive Substances-Conceptual Map. International Journal of Nursing, 2015. 2(2): p. 47-52.

2. Son, J., Perceptions and Challenges: Postpartum Care Among Korean Americans Through an Online Community. Journal of Transcultural Nursing, 2016. 27(3): p. 241-248.

3. Dennis, C.-L., et al., Identifying women at risk for sustained postpartum anxiety. Journal of Affective Disorders, 2017. 213: p. 131-137. 
4. Falah-Hassani, K., R. Shiri, and C.-L. Dennis, The prevalence of antenatal and postnatal co-morbid anxiety and depression: a meta-analysis. Psychological medicine, 2017: p. 1-13.

5. Gao, L.-I., et al., Effects of an interpersonal-psychotherapy-oriented postnatal programme for Chinese first-time mothers: a randomized controlled trial. International journal of nursing studies, 2015. 52(1): p. 22-29.

6. Meltzer-Brody, S., et al., Obstetrical, pregnancy and socio-economic predictors for new-onset severe postpartum psychiatric disorders in primiparous women. Psychological medicine, 2017. 47(8): p. 1427-1441.

7. Kronborg, H., I. Harder, and E.O. Hall, First time mothers' experiences of breastfeeding their newborn. Sexual \& Reproductive Healthcare, 2015. 6(2): p. 82-87.

8. Shrestha, S., K. Adachi, and M. Petrini, Factors associated with post-natal anxiety among primiparous mothers in Nepal. International nursing review, 2014. 61(3): p. 427-434.

9. Cattaneo, M.C., et al., The behavior over time of postnatal depression symptomatology and its early detection via the Edinburgh Postnatal Depression Scale: An Italian Iongitudinal study. International Journal of Advanced Nursing Studies, 2015. 4(1): p. 23.

10. Teychenne, M., et al., Associations between physical activity, television viewing and postnatal depressive symptoms amongst healthy primiparous mothers. Mental Health and Physical Activity, 2016. 10: p. 62-67.

11. Lanier, P. and M. Jonson-Reid, Comparing primiparous and multiparous mothers in a nurse home visiting prevention program. Birth, 2014. 41(4): p. 344-352.

12. Toohill, J., et al., Prevalence of childbirth fear in an Australian sample of pregnant women. BMC pregnancy and childbirth, 2014. 14(1): p. 275.

13. Faisal-Cury, A., et al., The relationship between depressive/anxiety symptoms during pregnancy/postpartum and sexual life decline after delivery. The journal of sexual medicine, 2013. 10(5): p. 1343-1349.

14. Kaitz, M., et al., Maternal anxiety, mother-infant interactions, and infants' response to challenge. Infant Behavior and Development, 2010. 33(2): p. 136-148.

15. Lai, Y.-L., et al., Postpartum fatigue, baby-care activities, and maternal-infant attachment of vaginal and cesarean births following rooming-in. Applied Nursing Research, 2015. 28(2): p. 116-120.

16. Wu, W.-R. and C.-H. Hung, First-time mothers psychiatric health status during the transition to motherhood. Community mental health journal, 2016. 52(8): p. 937-943.

17. Negron, R., et al., Social support during the postpartum period: mothers' views on needs, expectations, and mobilization of support. Maternal and child health journal, 2013. 17(4): p. 616-623.

18. Saligheh, M., et al., The relationship between postnatal depression, sociodemographic factors, levels of partner support, and levels of physical activity. Frontiers in psychology, 2014. 5.

19. Reid, K.M. and M.G. Taylor, Social support, stress, and maternal postpartum depression: $A$ comparison of supportive relationships. Social science research, 2015. 54: p. 246-262. 
20. Verreault, N., et al., Rates and risk factors associated with depressive symptoms during pregnancy and with postpartum onset. Journal of psychosomatic obstetrics \& gynecology, 2014. 35(3): p. 8491.

21. Biaggi, A., et al., Identifying the women at risk of antenatal anxiety and depression: a systematic review. Journal of Affective Disorders, 2016. 191: p. 62-77.

22. Yim, I.S., et al., Biological and psychosocial predictors of postpartum depression: systematic review and call for integration. Annual review of clinical psychology, 2015. 11.

23. Hayes, L.J., S.H. Goodman, and E. Carlson, Maternal antenatal depression and infant disorganized attachment at 12 months. Attachment \& human development, 2013. 15(2): p. 133-153.

24. Rallis, S., Psychological distress across pregnancy and postpartum: a prospective study. 2015, Deakin Univeristy.

25. Goldberg, L.R., The development of markers for the Big-Five factor structure. Psychological assessment, 1992. 4(1): p. 26.

26. Ozgoli, G., et al., A randomized, placebo-controlled trial of Ginkgo biloba L. in treatment of premenstrual syndrome. The Journal of Alternative and Complementary Medicine, 2009. 15(8): p. 845-851.

27. Zimet, G.D., et al., Psychometric characteristics of the multidimensional scale of perceived social support. Journal of personality assessment, 1990. 55(3-4): p. 610-617.

28. Edwards, L.M., Measuring perceived social support in Mexican American youth: Psychometric properties of the multidimensional scale of perceived social support. Hispanic Journal of Behavioral Sciences, 2004. 26(2): p. 187-194.

29. Salimi, A., B. Jokar, and R. Nikpoor, Internet connections in life: the role of perceived social support and loneliness in using internet. Psychol Stud, 2009. 5(3): p. 81-102.

30. Razurel, C., et al., Validation of the Postnatal Perceived Stress Inventory in a French Speaking Population of Primiparous Women. Journal of Obstetric, Gynecologic, \& Neonatal Nursing, 2013. 42(6): p. 685-696.

31. White, M. and G. Elander, Translation of an instrument. Scandinavian Journal of Caring Sciences, 1992. 6(3): p. 161-164.

32. Razurel, C., et al., Relation between perceived stress, social support, and coping strategies and maternal well-being: a review of the literature. Women \& health, 2013. 53(1): p. 74-99.

33. Billings, A.A., Psychometric Evaluation of the Wang Pregnancy Stress Scale: Revised for Taiwanese Women. Journal of nursing measurement, 2015. 23(3): p. 409.

34. Swartz, L., et al., Results from a randomized control trial of a parenting intervention for highly stressed families: Make Parenting A Pleasure. 2016.

35. Cheraghi, M., et al., Risk factors of postpartum depression in Ramhormoz city, Iran. Neuropsychiatria i Neuropsychologia, 2015. 10(1): p. 1. 
36. Kehoe, A., et al., Stress and coping in parents of newly born twins. Journal of Psychosomatic Obstetrics \& Gynecology, 2016. 37(3): p. 110-118.

37. Eddins, A., Attachments and the earliest moments of life: A literature review of the pre and immediate postnatal factors that influence relationships. 2014: Biola University.

38. Giallo, R., et al., In survival mode: mothers and fathers' experiences of fatigue in the early parenting period. Journal of reproductive and infant psychology, 2013. 31(1): p. 31-45.

39. Nanni, R.C. and A. Troisi, Maternal attachment style and psychiatric history as independent predictors of mood symptoms in the immediate postpartum period. Journal of Affective Disorders, 2017. 212: p. 73-77.

40. Woodward, L.J., et al., Very preterm birth: maternal experiences of the neonatal intensive care environment. Journal of perinatology: official journal of the California Perinatal Association, 2014. 34(7): p. 555.

41. Garner, C.D., et al., Obese women experience multiple challenges with breastfeeding that are either unique or exacerbated by their obesity: Discoveries from a longitudinal, qualitative study. Maternal \& child nutrition, 2017. 13(3).

42. Fox, R., S. McMullen, and M. Newburn, UK women's experiences of breastfeeding and additional breastfeeding support: a qualitative study of Baby Café services. BMC pregnancy and childbirth, 2015. 15(1): p. 147.

43. Ong, S.F., et al., Postnatal experiences and support needs of first-time mothers in Singapore: $A$ descriptive qualitative study. Midwifery, 2014. 30(6): p. 772-778.

44. Wambach, K., et al., Exclusive breastfeeding experiences among Mexican American women. Journal of Human Lactation, 2016. 32(1): p. 103-111.

45. Razurel, C., et al., Stressful events, social support and coping strategies of primiparous women during the postpartum period: a qualitative study. Midwifery, 2011. 27(2): p. 237-242.

46. Hinton, L., L. Locock, and M. Knight, Support for mothers and their families after life-threatening illness in pregnancy and childbirth: a qualitative study in primary care. Br J Gen Pract, 2015. 65(638): p. e563-e569.

47. Dennis, C.L. and L. Ross, Women's perceptions of partner support and conflict in the development of postpartum depressive symptoms. Journal of advanced nursing, 2006. 56(6): p. 588-599.

48. Schlagintweit, H.E., K. Bailey, and N.O. Rosen, A new baby in the bedroom: Frequency and severity of postpartum sexual concerns and their associations with relationship satisfaction in new parent couples. The journal of sexual medicine, 2016. 13(10): p. 1455-1465.

\section{Tables}


Table 1. Topics and Methods of family member's counseling to reduce postpartum perceived stress

\begin{tabular}{|c|c|c|c|c|}
\hline $\begin{array}{l}\text { Weekly } \\
\text { Session }\end{array}$ & $\begin{array}{l}\text { Title of } \\
\text { session }\end{array}$ & Topics & $\begin{array}{l}\text { Duration } \\
\text { (Min) }\end{array}$ & Methods \\
\hline 1 & $\begin{array}{l}\text { Fatigue and } \\
\text { organization } \\
\text { at home }\end{array}$ & $\begin{array}{l}\text { Regulation sleep schedule to deal with } \\
\text { fatigue } \\
\text { Plans to adapt to a shortage of time at } \\
\text { home. } \\
\text { Cope with daily routine schedule changes } \\
\text { Satisfy baby demands } \\
\text { Manage the house }\end{array}$ & $60-90$ & \multirow{6}{*}{$\begin{array}{l}\text { Short lectures, } \\
\text { Group discussion } \\
\text { Sharing positive and } \\
\text { constructive experiences } \\
\text { with each other } \\
\text { Reviewing Negative } \\
\text { experiences and training } \\
\text { effective strategies } \\
\text { Flash cards } \\
\text { Power point }\end{array}$} \\
\hline 2 & $\begin{array}{l}\text { Relationship } \\
\text { with baby }\end{array}$ & $\begin{array}{l}\text { Empowering mother to take care of baby } \\
\text { Awareness of baby's health and attention } \\
\text { to abnormal symptoms } \\
\text { Teaching the mother how to take care of } \\
\text { the baby (bath, umbilical cord, diaper } \\
\text { change) } \\
\text { Dealing with postpartum blues, and } \\
\text { negative thoughts } \\
\text { Communicate with closed relatives }\end{array}$ & $60-90$ & \\
\hline 3 & $\begin{array}{l}\text { Relationship } \\
\text { with body }\end{array}$ & $\begin{array}{l}\text { Tips to reduce episiotomy pain and } \\
\text { recovery } \\
\text { Introducing post- partum exercise to } \\
\text { restore the body to its normal state. }\end{array}$ & $60-90$ & \\
\hline 4 & $\begin{array}{l}\text { Feeding the } \\
\text { baby }\end{array}$ & $\begin{array}{l}\text { Choosing the right position during } \\
\text { breastfeeding to reduce pain } \\
\text { How to breastfeed properly } \\
\text { How to get family support to successful } \\
\text { breastfeeding } \\
\text { How to choose the right information from } \\
\text { the different advices proposed by } \\
\text { different caregivers. }\end{array}$ & $60-90$ & \\
\hline 5 & Future plans & $\begin{array}{l}\text { Back to normal daily activities } \\
\text { Tips for back to outdoor activities. }\end{array}$ & $60-90$ & \\
\hline 6 & $\begin{array}{l}\text { Relationship } \\
\text { with } \\
\text { Husbands }\end{array}$ & $\begin{array}{l}\text { Tips for improving and recovering sexual } \\
\text { intimacy } \\
\text { Teaching fathers to bond with baby }\end{array}$ & $60-90$ & \\
\hline
\end{tabular}

Table2: Demographic, clinical characteristics and family support in intervention and control group 


\begin{tabular}{|c|c|c|c|c|c|}
\hline able & & Intervention $\mathrm{N}(\%)$ & Control N(\%) & $\mathrm{X}^{2}$ & $\mathrm{P}$ \\
\hline \multirow[t]{3}{*}{ san's age } & $20-24$ & $91(55.5)$ & $94(56.6)$ & 2.8 & \multirow[t]{3}{*}{0.43} \\
\hline & $25-29$ & $39(23.8)$ & $49(27.7)$ & & \\
\hline & $30-34$ & $34(20.7)$ & $26(15.7)$ & & \\
\hline \multirow[t]{2}{*}{ tion } & Yes & $23(14)$ & $33(19.9)$ & 2 & \multirow[t]{2}{*}{0.18} \\
\hline & No & $141(86)$ & $133(80.1)$ & & \\
\hline \multirow[t]{2}{*}{ sfaction of fetal sex } & Yes & $144(87.8)$ & $158(95.2)$ & 1.26 & \multirow[t]{2}{*}{0.01} \\
\hline & No & $20(12.2)$ & $8(4.8)$ & & \\
\hline \multirow[t]{3}{*}{ sation status } & Primary & $25(15.2)$ & $21(12.7)$ & 1.85 & \multirow[t]{3}{*}{0.39} \\
\hline & High school & $49(29.9)$ & $61(36.7)$ & & \\
\hline & College certificate & $90(54.9)$ & $84(50.6)$ & & \\
\hline \multirow[t]{3}{*}{ Iomic status } & Good & $29(17.7)$ & $39(23.5)$ & 1.84 & \multirow[t]{3}{*}{0.4} \\
\hline & Fair & $96(58.5)$ & $93(56)$ & & \\
\hline & Poor & $39(23.8)$ & $34(20.5)$ & & \\
\hline \multirow[t]{2}{*}{ ness status } & Employed & $46(28)$ & $34(20.5)$ & 2.57 & \multirow[t]{2}{*}{0.12} \\
\hline & Housewife & $118(72)$ & $132(79.5)$ & & \\
\hline \multirow[t]{5}{*}{ band's age } & $20-24$ & $24(14.6)$ & $27(16.3)$ & $0 / 5$ & \multirow[t]{5}{*}{0.97} \\
\hline & $25-29$ & $71(43.3)$ & $68(41)$ & & \\
\hline & $30-34$ & $49(29.9)$ & $48(28.9)$ & & \\
\hline & $35-39$ & $14(8.5)$ & $15(9)$ & & \\
\hline & $>40$ & $6(3.7)$ & $8(4.8)$ & & \\
\hline \multirow[t]{3}{*}{ band's education } & Primary & $20(12.2)$ & $15(9)$ & 2.5 & \multirow[t]{3}{*}{0.29} \\
\hline & High school & $58(53.4)$ & $72(43.4)$ & & \\
\hline & College certificate & $86(52.4)$ & $79(47.6)$ & & \\
\hline \multirow[t]{2}{*}{ band's job } & Nongoernmental & $101(61.5)$ & $100(61)$ & 1.83 & \multirow[t]{2}{*}{0.016} \\
\hline & Governmental & $63(38.5)$ & $64(39)$ & & \\
\hline \multirow[t]{2}{*}{ sing status } & Tenant & $136(83)$ & 78(78.8) & 0.5 & \multirow[t]{2}{*}{0.4} \\
\hline & Owner & $28(17)$ & $35(21.2)$ & & \\
\hline riage Duration(SD) & $3.20 \pm 1.63$ & $3.13 \pm 1.14$ & & 0.7 & 0.91 \\
\hline ily support(SD) & $12.90 \pm 5.46$ & $12.51 \pm 5.42$ & & 0.4 & 0.56 \\
\hline
\end{tabular}

Table 3: Changes Perceived stress scores in intervention and control group 


\begin{tabular}{|c|c|c|c|c|}
\hline $\mathrm{P}$ & $\mathrm{T}$ & $\begin{array}{c}\text { Post-intervention } \\
\text { (Mean (SD }\end{array}$ & $\begin{array}{l}\text { Pre-intervention } \\
\text { (Mean (SD }\end{array}$ & \\
\hline & & & & Perceived stress total \\
\hline$<0.001$ & -8.93 & $81 / 40 \pm 24 / 82$ & $101 / 63 \pm 13 / 47$ & Intervention group \\
\hline \multirow[t]{2}{*}{$0 / 68$} & -0.41 & $99 / 97 \pm 15 / 3$ & $100 / 16 \pm 15 / 88$ & Control group \\
\hline & & & & (Fatigue(5-25 \\
\hline $0.001>$ & $6.55-$ & $15.08 \pm 6.75$ & $20.76 \pm 6.14$ & Intervention group \\
\hline \multirow[t]{2}{*}{0.78} & $0.27-$ & $20.20 \pm 6.30$ & $20.22 \pm 6.26$ & Control group \\
\hline & & & & (Relationship with baby(6-30 \\
\hline $0.008>$ & $2.63-$ & $17.77 \pm 9.53$ & $21.18 \pm 7.05$ & Intervention group \\
\hline \multirow[t]{2}{*}{0.31} & $1-$ & $20.77 \pm 6.95$ & $20.68 \pm 6.99$ & Control group \\
\hline & & & & Relationship with body(5-25) \\
\hline $0.001>$ & $6.43-$ & $16.09 \pm 5.85$ & $19.53 \pm 1.12$ & Intervention group \\
\hline \multirow[t]{2}{*}{$0.37>$} & $0.88-$ & $18.76 \pm 5.05$ & $18.80 \pm 4.91$ & Control group \\
\hline & & & & (Feeding the baby (4-20 \\
\hline 0.03 & $2.16-$ & $10.61 \pm 4.05$ & $12.20 \pm 5.65$ & Intervention group \\
\hline \multirow[t]{2}{*}{0.19} & $1.31-$ & $11.99 \pm 5.61$ & $12.04 \pm 5.53$ & Control group \\
\hline & & & & (Future plan (3-15 \\
\hline $0.001>$ & $10.29-$ & $8.02 \pm 2.45$ & $12.43 \pm 2.24$ & Intervention group \\
\hline \multirow[t]{2}{*}{0.31} & $1-$ & $11.99 \pm 2.07$ & $11.98 \pm 5.61$ & Control group \\
\hline & & & & Relationship with partner \\
\hline $0.001>$ & $10.83-$ & $13.82 \pm 1.03$ & $16.91 \pm 0.98$ & Intervention group \\
\hline 0.55 & $0.58-$ & $16.43 \pm 3.44$ & $16.25 \pm 3.45$ & Control group \\
\hline
\end{tabular}




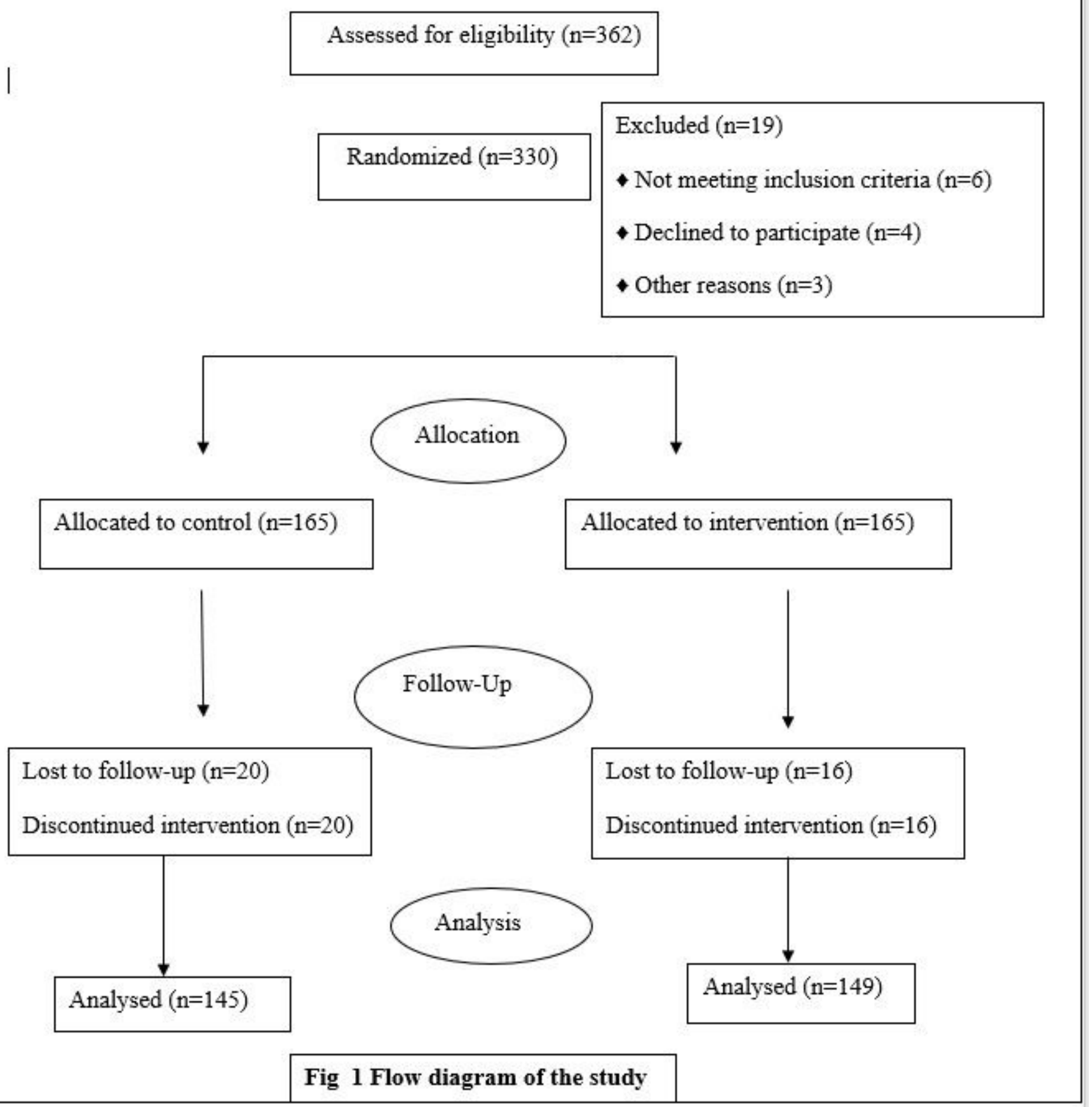

\section{Figure 1}

Family Involvement, Postnatal Perceives Stress, Pregnancy 